\title{
Assessing Exposures in the United Kingdom's Armed Forces - A Review of Systems that Collect Data Useful for Exposure Assessment
}

\author{
AC Capleton, SD Short, L Rushton
}

\begin{abstract}
The ability to assess the exposure of individuals or groups is a critical element in any effective health surveillance system, as it provides the opportunity to identify the causes of ill health, the levels of exposure resulting in ill health and, through controlling exposures, to protect the health of Service personnel. As part of a wider programme to enhance the health surveillance capabilities of the Defence Medical Services, a project was undertaken to assess the collection and retention of data for exposure assessment in the United Kingdom's Armed Forces. The systems investigated include those for health, safety and environment policy, personnel and pay, medical records, environmental and occupational monitoring and historical records. It was found that the use of many systems for exposure assessment would be hampered by inconsistencies in the data collected, poor accessibility and linkage, and variability in the retention of the data. This paper highlights some of the problems that limit the usefulness of the record systems for exposure assessment and summarizes the principal recommendations made for enhancing the systems to better facilitate health surveillance.
\end{abstract}

Keywords: Exposure data, exposure assessment, health surveillance, epidemiology, occupational health, Ministry of Defence.

\section{Introduction}

Health surveillance is a critical element of any comprehensive military health care system and should facilitate "...the routine systematic collection, analysis, interpretation and reporting of standardised, population based data for the purpose of characterising and countering threats to the military population's health." (1).

AC Capleton BSc MSc SD Short BSc MSc L Rushton BA MSc PhD CStat

MRC Institute for Environment and Health

University of Leicester, 94 Regent Road, Leicester, LE1 7DD
The ability to identify, define and assess the exposure of individuals or populations to health hazards is a central element to such a health surveillance system. This is essential in order to be able to identify the causes of ill health, the levels of exposure resulting in ill health and to protect the health of Service personnel, through controlling exposures and evaluating control strategies.
Exposure is defined as a contact over time and space between a person and one or more biological, chemical or physical agents (2); tố this we would also add psychological agents $\overrightarrow{0}$ Assessing exposures not only requires data to characterise the exposure of concern, but also data to identify the population of interest, to link the population with the exposure of concern (e.g. by using job title, location or deployment data), and to link to any potential health outcome. These datac need to be of adequate quality and type, $\dot{\varnothing}$ sufficiently accessible and retained for long음 enough that, ideally, any potential health outcome, with any latency period, can be investigated with respect to the exposures of $\frac{0}{0}$ concern (3). Indeed a lack of exposure data $\mathbb{\Phi}$ is frequently cited as the principal limiting $N$ factor in establishing exposure-response relationships in studies of occupational health (4) and, consequently, in establishing causality.

As part of a wider project to enhance the health surveillance capability of the Defence $\stackrel{\mathbb{D}}{\varnothing}$ Medical Services, a project was $\overrightarrow{\vec{O}}$ commissioned, by the Health Surveillance Steering Group of the Surgeon General's Department, to objectively assess systems in the United Kingdom's (UK) Armed Forces for the collection and retention of exposure data. The main objectives of the study were to:

- determine current practice for both the collection and retention of exposure data and consider how these may be improved;

- identify the linkages and overlaps with health data and information collected in other systems within the Armed Forces;

- consider the design and complexity of research for which exposure data might be required; and

- provide recommendations for the format, collection and retention of exposure data.

This paper summarizes the principal findings and recommendations of the study (5).

\section{Methodology}

In order to assess systems for collecting exposure data, a series of visits to Ministry of Defence (MOD) Units, with potential involvement in the collection and retention of exposure data, and some selected examples from civilian industry, were made to: 
- establish what systems (procedures, record and computer systems) are used that collect exposure information;

- gain a detailed understanding of each system; and

- evaluate each system for the purpose of exposure assessment.

The MOD Units visited were identified by a variety of means based on knowledge of the data necessary for exposure assessment, consultation with staff of the Defence Evaluation and Research Agency (DERA), recommendations made by Units visited and the Internet. Civilian industries were selected on the basis of comparability to the Armed Forces and through professional contacts (information derived from these visits are not discussed here).

Before visiting a Unit or industry a summary, outlining the project's aims and objectives, was sent together with a letter explaining the purpose of the visit. During each visit a semi-structured interview was conducted with key staff to gain an understanding of each system that collected exposure information. A standard interview checklist was developed and used in all the interviews to minimise interviewer bias, facilitate consistency and comparabilit between interviews and to ensure importa issues were not omitted. After each visit, $\mathbf{3}$ draft visit report was sent back to each Un® or industry, in order that the report accuracy could be checked and commenteg upon. Most Units and industries returned these draft visit reports and any commen received were taken into account. Where reply was received, it was assumed that the interpretation in the draft was correct.

The visit reports were used as the basis qualitatively assess each of the systems thä, intentionally or incidentally, collect da $\overrightarrow{\mathrm{f}}$ relevant to exposure assessment. The system were assessed according to the type of daf collected, the accessibility of the data, linka of data to health or other records and the retention and archiving of data for future use Based on the assessment of each systents recommendations were developed as to ho\& the collection and retention of exposure da\& in the UK Armed Forces could be enhanced.

In total 33 visits were made between May 1999 and October 2000. Table 1 lists to Units and industries visited, sub-divided in seven categories.

Table 1. Ministry of Defence Units and civilian industries visited

Ministry of Defence Unit / Civilian Industry

Health, safety and environment policy

Directorate of Safety, Environment and Fire Policy

Chief Environment and Safety Officers (Army and Royal Air Force (RAF))

Army Medical Directorate, Medical Intelligence

Directorate of Defence Logistics Safety

Personnel and pay administration systems

Armed Forces Personnel Administration Agencies (Army - Worthy Down; Royal Navy - Centurion; RAF -

Innsworth)

Unit Computing System (Army)

Medical Records

Surgeon General's Department

Army Medical Directorate

Director of Health, HM Naval Base Portsmouth

Directorate of Primary Health Care, RAF Innsworth

Occupational exposure and environmental monitoring data

Defence Evaluation and Research Agency Radiological Protection Service

Medical Operational Planning

Defence Logistics Organisation Equipment Support (Land), Hazardous Materials

Army Environmental Monitoring Team, Keogh Barracks

Army Environmental Health Team, Imphal Barracks, York

Occupational Health Centre, HM Naval Base Portsmouth

Institute of Naval Medicine

Flag Office Surface Flotilla Health and Safety Team, HM Naval Base Portsmouth

RAF Institute of Health

Historical records

Army, Naval and Air Historical Branches

Users of Armed Services information systems

War Pensions Agency

Gulf Veterans' Illness Unit

Defence Analytical Services Agency (two visits)

Examples of occupational health and exposure data systems in civilian industry

Rolls-Royce

Imperial Chemical Industries

Westlakes Scientific Consulting Ltd

Health and Safety Executive (National Exposure Database) 


\section{Results}

Every attempt has been made to ensure that the data represented here are as correct and complete as possible. Due to the time available for the project it was only possible to make a limited number of visits, and hence not all systems that collect relevant data may be represented here. Furthermore, during the project it was clear that some systems were due to be changed or were undergoing change - the following results pertain to the systems at the time of our visits.

\section{Health, safety and environment policy}

There is limited direct collection of exposure data amongst these Units. However, the visits provided an understanding of how Safety, Health, Environment and Fire (SHEF) policy is interpreted and implemented and the influences on exposure data collection policy in the Armed Forces. The primary influences on the collection or exposure data in the Armed Forces are:

- protection of the health of Service personnel and enhancement of business efficiency, in order to maximise the number of individuals operationally fit; and

- legislative requirements for health and safety, which may involve collection of exposure data to demonstrate compliance with regulatory limits or procedures.

Other influences can include such issues as ensuring fair and appropriate compensation.

The source of all policy underpinning the collection of exposure data in the area of SHEF is the Directorate of Safety, Environment and Fire Policy. Once policy is agreed it is written into a Joint Service publication (JSP), for example JSP 375 , the MOD Health and Safety Handbook, and applies equally in the UK and overseas. The implementation of the policy within the MOD is the responsibility of the Top Level Budget holders. In each Service the responsibility is delegated to each Service Chief Environment and Safety Officer, and each Service implements the policy according to their own arrangements. For example, the Royal Air Force (RAF) and Royal Navy (RN) interpret the requirements of JSP 375 into Service specific publications i.e. Air Publication 400 and Book of Reference 9147 respectively, whereas the Army use JSP 375 directly. This can lead to variations in the implementation of the policy between the Services, and hence inconsistencies in the collection of some exposure data. An example of this occurs in the accident reporting between Services: the RAF have a single accident reporting form on which all accidents, regardless of severity, are reported, whereas the Army currently has 24 ways in which accidents can be reported and choose only to report accidents resulting in one or more hours off duty. The variations in interpretation and implementation of policy also lead to variations between the Services in the retention and archiving of records that may contain useful exposure data. There is, however, increasing emphasis on standardisation of policy and practice and, at the time of our visits, JSP 375 was being revised, which may lead to changes in the organisation and implementation of policy across the Services.

\section{Personnel and pay administration systems}

The Armed Forces Personnel and Administration Agencies (AFPAAs) collect a large amount of data relevant to exposure assessment, including information necessary to identify individuals and enumerate a cohort, job task and job history data, and movement and location data, all of which may be used as surrogates for exposure in health surveillance and epidemiology.

Identifier information collected by the AFPAAs include the Service number, which is a unique identification number issued to every member of the Services. The structure of this number differs between the Services, and between officers and ranks. The number may also change during an individual's career, should they be commissioned as an officer. This is most pronounced in the Army and RN where, on commissioning, a completely new Service number is issued, whereas in the RAF the number only changes slightly by the proximal character moving to become the terminal character. National Health Service (NHS) numbers, which could also be used as a unique identifier, or to link exposure records to civilian health records, are inconsistently recorded between and within the Services. For example, in the Army and RAF only NHS numbers for officers are held on the mainframe computer; for ranks they are only recorded in their paper personnel records.

The job task and job history information collected is largely in the form of a list of postings, training records and in some cases job titles (particularly in the RAF and $\mathrm{RN}$ ), which define approximately the tasks an individual may have been expected to perform. However, a job title or training may not necessarily reflect the actual tasks an individual carried out, since this is ultimately at the discretion of the Commanding Officer of the Unit.

The AFPAA systems also collect some movement and location data. For all Service personnel, their postings are recorded, although, in practice, this may not correlate to their actual geographical location, and a posting may span a period of several years. More detailed movement and location data may be recorded at a Unit level, but this may not be included in the main AFPAA systems. An exception to this is the $\mathrm{RN}$, for whom 
Table 2. Archiving of personnel and pay data in the UK Armed Forces

\begin{tabular}{ll}
\hline Service & Records \\
\hline Army & Personnel and pay files
\end{tabular}

Archiving of records

Royal Air Force

Personnel and pay files

Computer records retained. Paper personnel file retained until no Reserve value, then archived.

Officers: Computer records archived. Paper personnel files retained indefinitely.

Airmen/Airwomen: Computer records archived. Paper personnel records retained for seven years after last entry, and then destroyed. An A3 Summary sheet for each individual is retained indefinitely.

Royal Navy Personnel files

Computer files printed out and both computer and paper file archived

Pay Files

Data progressively weeded until 10 years post discharge, when record archived.

location determines pay allowances. Hence, when an individual changes location, for example, from sea to shore, a Movement Occurrence Report (MOR) is made, which notifies the Pay system of the change of location and alters the individual's pay allowances accordingly. These MORs are stored as part of the individual's Pay file.

The retention and archiving of the pay and personnel records is variable between the Services and between officers and ranks and is summarised in Table 2 .

\section{Medical records}

Collection of data relevant for exposure assessment in medical records is limited, not surprisingly, because their primary function is to provide a medical history. Medical records are made on a series of F Med forms (paper records) that are used in a standard manner across all three Services. An individual's medical records are retained in a Personal Medical Record (F Med 4) which, on discharge, is archived indefinitely. Computer medical records may also exist, although their use is variable across the Services, and they do not usually provide a complete primary health care record. On discharge, the computer medical records are also archived indefinitely. Medical records are usually stored and archived according to name and Service number.

Medical records of relevance to exposure assessment include vaccination records, periodic medical fitness assessments (which may record smoking status and alcohol intake), and records of health or medical surveillance. In particular, the Radiation Medical Examination Record (F Med 291C), Control of Substances Hazardous to Health (COSHH) Medical Surveillance Record (F Med 143A), COSHH Regulations - Personal Exposure and Health Surveillance Record (MOD Form 933F), and Audiogram (F Med 242) all identify a hazardous exposure(s) and give some indication of the location and nature of the work resulting in the exposure, although only the F Med 291C provides any quantitative exposure data.
Occupational exposure and environment monitoring data

Chemical exposure data: A considerab危 amount of data on exposure to chemicals are collected throughout the Armed Forces under the Control of Substances Hazardoqs to Health (COSHH) Regulations 1999, ard similar statutory instruments, such as tlo Control of Lead at Work Regulations 198\%. Under $\mathrm{COSHH}$, assessments are made for all substances used in the Armed Forces that are identified under $\mathrm{COSHH}$ as hazardoes to health. The assessments effectived, constitute a paper record of an assessment of exposure and include data on tog substance(s) of concern, the route(s) Ef exposure, the process(es) resulting 类 exposure and the location of the process(e The individuals or jobs likely to receipe exposure are not recorded. The assessmer $\overrightarrow{\widehat{\phi}} \mathrm{s}$ are made on a standard MOD form (COSHH Assessment Form, MOD For要 911), and are retained locally and reviewejd periodically. They are not generally linked personnel or medical records. Only t current assessment for a substance/process retained; unless there has been an accider old assessments are discarded.

Some direct measurements of exposure collected, particularly where a COSH assessment is complex, there is a need $\mathrm{m}_{0}$ demonstrate compliance with exposuge limits, or there is a general concern abot exposure. This is usually in the form of routine air monitoring, biologigyl monitoring, or a discrete study of a particular exposure issue. Routine air monitoring 야 recorded on a $\mathrm{COSHH}$ - Routine Exposigy Monitoring Form (MOD Form 933E), and records details of the substance(s) a和 individuals or process(es) monitored, the location of monitoring, and the results of t聚 monitoring. On completion, the form $\stackrel{\circ}{\overparen{S}}$ retained by the line manager concerne alongside the relevant $\mathrm{COSHH}$ assessment. Individuals exposed to substances such \&s lead, mercury or thallium may have thê․ exposure assessed by biological monitorint The results of lead biomonitoring should included in each individual's medical 
records, and all biomonitoring results are reported back to the line manager concerned. Storage and retention of these exposure data are variable, depending on the type of data, and the Service. Finally, some exposure data are collected as a result of ad hoc studies on particular exposure issues of interest or concern. The data generated are generally presented in a discrete paper report, copies of which are provided to the customer and retained by the Unit making the measurements.

Data on exposure to asbestos are not routinely collected. However, if an individual suspects that they have been exposed to asbestos, they may choose to complete an Asbestos Personal Record Annotation form (MOD Form 960). This is a self-certification form, a copy of which is retained in the individual's personnel records, and the individual may also choose to have a copy placed in their medical records.

Other areas of routine chemical exposure data collection include the continuous and periodic monitoring of atmospheres in submarines. These data are recorded in a submarine Atmosphere Control Log that, on completion, are entered into a database and retained indefinitely by the Institute of Naval Medicine (INM). Drinking water samples are also collected from ships and submarines (subject to assistance from the fleet), quarterly for bacteriological analyses and annually for chemical analyses, with the results being retained indefinitely at the INM.

A number of environmental chemical measurements are made on an ad hoc basis to address specific pollution incidents, problems or concerns, or as part of an ongoing MOD assessment of land quality. In these cases, the results of the monitoring data are recorded in a paper report and retained by the Unit requesting and the Unit undertaking the measurements.

Noise and vibration exposure data: There are two areas of noise exposure data collection in the Services. These are the routine Noise Assessment Record (MOD Form 945), and specialist noise assessments. Routine noise assessments are made under the Noise at Work Regulations 1989 and record the noise levels measured, the location of the assessment, an estimate of the number of employees exposed and the duration of exposure. The assessments are retained by the line manager responsible for the area and a copy should be forwarded to a Service specific recipient (e.g. INM or Command Principal Medical Officer (RAF)), as specified on the form. The assessments should be reviewed every two years and a repeat assessment carried out every five years. The serial number (consisting of the Unit Identification Number and a reference number) of a repeat assessment should be recorded on the previous assessment and vice versa, thus creating a continuous no assessment record for a location, process, piece of equipment. Individuals or job tasks exposed are not recorded.

Specialist noise surveys are carried ơ where an initial assessment indicates tloat noise levels exceed a daily personal expostase level of 105 decibels, or the noise assessment requires particular expertise, for example, weaponry, impulsive, pure tone, infra- Ir ultra sound. Other specialist assessmer⿳亠口冋ts may include some environmental no $\mathrm{T}$ monitoring. Assessments of vibration are oll specialist assessments and usually incluge assessments of equipment or transpo $\overrightarrow{\mathbb{Q}}$. These specialist assessments are reported $\overrightarrow{a s}$ discrete paper reports to the Unit requestigg and the Unit making the measurements.

Radiological exposure data: Monitoring of radiological exposures of Servią personnel is co-ordinated by the DEFo Radiological Protection Service (DRP\$. Dosemeters are issued, on a monthly basis $\Phi_{0}$ all Service personnel, who have been identified as being routinely exposed $\&$ radiation. The results of the monitoring age maintained at DRPS as paper records, on $\mathscr{Q}_{a}$ microfiche and on an Oracle database. TH dose record for each individual include comprehensive personnel details, a yearl apportioned dose breakdown, results of every dosimetre analysed, and details of क्षा changes made to the record. Whege individuals have been exposed to radiation from previous employment, a summary off their dosimetry record is obtained from to previous Approved Dosimetry Service ar incorporated as part of their dosimetiy record. Hence DRPS maintain a comple record of an individual's lifetina occupational exposure to radiation until th leave the Service. These records are n⿳⺈⿴囗十灬t linked to personnel records, but are linked medical records through the F Med 291C. is current MOD policy to retain dosimetry records indefinitely.

In addition to the personal dosimetri, some monitoring of environmental radiation may be carried out, for example, for indo radon. However, the maintenance of th records of such monitoring is the responsibility of the Unit carrying out thy monitoring and not DRPS.

\section{Historical records}

Historical records are made by each of the Services, and although not a primary source of exposure data, they can contain usefie information pertinent to exposu苑 assessment, such as data on exceptional $\stackrel{\vec{\omega}}{\mathrm{a}}$ unusual exposures, for example, accidente incidents resulting in casualties, operation duties etc. These records are Unit based and differ considerably in their contens. frequency and period of completion and 晞 their retention. Examples of the main 
Table 3. Summary of principal historical records made by the UK Armed Forces

\begin{tabular}{ll}
\hline Record & Completion \\
\hline Army Commander's Diary & $\begin{array}{l}\text { Completed in times of } \\
\text { operation on daily basis }\end{array}$ \\
$\begin{array}{ll}\text { Unit Historical Record } & \begin{array}{l}\text { Completed on an annual } \\
\text { (Army) }\end{array}\end{array}$
\end{tabular}

Ship's Log

Report of Proceedings (Royal Navy)

RAF Operations Record Book
Completed three times each day

No fixed time period for completion

Completed on a monthly basis

Content
$\begin{aligned} & \text { Summarises major events } \\ & \text { at Unit level }\end{aligned}$

Non-operational report summarising major events at Unit level

Record of ship's location and brief details of events

Narrative account of activities of Unit

Standard form giving an account of a Unit's activities, and details of any significant flights made
Retention

Retained at Unit level until being archived at Hayes

Retained at Unit level until being archived at Hayes

Sent through Fleet to Admiralty archive at Haye

Sent to relevant Flag Office and the Naval Historical Branch

Sent to Air Historical Branch and after 30 years forwarded to Public Records Office, security considerations permitting historical records produced are summarised in Table 3.

\section{Other records}

Other areas that may be pertinent sources of exposure data include procurement records and records pertaining to chemical weapon exposures. However, due to the constraints of time, it was not possible to assess these areas.

\section{Discussion}

All the systems assessed had some limitations with respect to the collection and retention of data for exposure assessment. However, this is not altogether surprising since, for most of the systems assessed, the use of the information in exposure assessment is only a secondary use of the data, and probably was not anticipated in the original design of the system. The comments or criticisms presented below are solely from the perspective of exposure assessment.

A summary of the main strengths and weaknesses of each area of data collection assessed is presented in Table 4. In particular, systems often had limitations with respect to the type, accessibility, linkage and retention of data useful for exposure assessment; examples of these limitations, and some of the main recommendations from our study are given below. A complete discussion and list of the recommendations can be found in the full report (5).

There were a number of common limitations that were identified in the majority of the systems assessed. In particular, different systems were often used in the different Services for the same purpose, for example, three different pay and personnel systems, and usually little consideration had been given to the potential secondary uses of the data collected when the systems were designed. These limitations would hinder any tri-Service study of exposure and health and important data necessary to assess exposures may not have्द been collected in all the systems. Hence, weo suggest that, where possible, consider의 ation should be given to the development of tri-Service data systems, with os common data set. Also the purpose of each data item collected should be clearly defined, with full consideration given to the potential secondary uses of the data.

Type of data collected

A broad range of data useful for exposurö assessment are collected throughout the UK Armed Forces, including demographic dat $\vec{F}$ and data on exposures to specific hazards $\exists$ However, a significant limitation is the lack o a unique means of identifying an individual. throughout their Service career. This is no provided by the Service number because the number changes on commissioning, or if a a individual moves between Services. Hence ֻٕల complete follow-up of such individuals fo $\vec{F}$ epidemiological study would be difficult. Ars alternative identifier could be the NHS number, which would remain consisten? throughout an individual's career, and whicto would also facilitate follow-up in civilian life We, therefore, propose that there should be a unique way of identifying each individual that does not changer throughout his or her Service careeio (and possibly beyond).

There is also a lack of detailed dato pertaining to the jobs or tasks carried out bye individuals, and the location and movements? of individuals. Much health surveillance ando exposure assessment requires such data too define groups needing surveillance and as

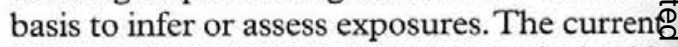
lack of detailed data would impede health surveillance if, for example, it was necessaryo to study the health of those returning from particular deployment or location (e.g. the Gulf), or undertaking specific tasks (e.g assisting with disposal of foot and mouth 
Table 4. A summary of the strengths and weaknesses of data systems of the UK Armed Forces from the perspective of exposure assessment

\begin{tabular}{ll}
\hline Area visited & $\begin{array}{l}\text { Generic function/ } \\
\text { purpose of Units }\end{array}$ \\
\hline $\begin{array}{l}\text { Health, safety and } \\
\text { environment policy }\end{array}$ & $\begin{array}{l}\text { To interpret and implement } \\
\text { health, safety, environment } \\
\text { and fire policy }\end{array}$
\end{tabular}

$\begin{aligned} & \text { Exposure data } \\ & \text { collected/system used }\end{aligned}$
$\begin{aligned} & \text { Mainly policy orientated } \\ & \text { work, hence limited direct } \\ & \text { collection of exposure data }\end{aligned}$

Strengths of datal system

Single source of policy on Safety, Health, Environment and Fire issues

Personnel and pay administration systems
Pay and personnel systems that collect and store demographic, identifier,

To assess correct pay and pension entitlement for Service personnel and provide a system to underpin job task, job history, and the posting of personnel. movement and location data
Comprehensive collection and retention of $\begin{array}{ll}\text { and retention of } & \text { necessarily a unique } \\ \text { demographic data collected } & \text { identifier. Variations in }\end{array}$ on all Service personnel

Service numbers not data collected between

Weaknesses of datal system

Separate interpretation of policy may lead to variations in implementation officers and ranks and between Services. Variations in retention and archive policy between officers and ranks and between Services

Medical records

To provide complete primary health care record for all Service personnel
Vaccination data, and medical and health surveillance data resulting from exposure to specific hazards e.g. radiation. Additional data may include confounder data e.g. smoking status and alcohol consumption

Occupational exposure and data

To help control the exposure of Service personnel to hazardous agents
Data on exposure to chemicals, noise, vibration, radiation and other more generic hazards

Data collected may include exposure data pertaining to rare or unusual events, e.g accidents
To collect historical records and to respond to official and public queries
Identical medical forms used across all three Services

Access to records according to an exposure or health endpoint is difficult. Little or no linkage of health surveillance data with personnel or exposure records

Considerable amount of data collected on exposure through risk assessments and routine monitoring of exposures

Useful source of data on unusual or rare exposures, or exposures encountered in operational situations infected animals). We, therefore, suggest consideration should be given to the development of a classification system that more accurately reflects the jobs and task carried out. We also propose that posting, movement and detachment information should be more comprehensively and consistently recorded.

\section{Accessibility of data}

The ability to readily access data is vital in order to assess exposures of groups or individuals, and to facilitate epidemiological study. Generally, the accessibility of data useful for exposure assessment was found to be poor, especially retrospectively. For example, a large number of exposure measurements are made both routinely, for example, as part of $\mathrm{COSHH}$ assessments, or more infrequently, for example, specialist assessments. However, there is no easy way of accessing this data, since much of it is stored on paper records or disaggregated databases. Problems similar to this have been overcome in civilian industries through the development of central databases, such as the National Exposure Database, maintained by the Health and Safety Executive (6). Consideration should, therefore, be given to developing a centralised triService database of exposure measurements, and/or exposure reports with a well-defined minimum dataset, and data quality criteria, to facilitate greater access to the available data.

\section{Linkage of data}

Linkage of disaggregated data is vital so that it is possible to retrospectively assess exposure (1), to relate the exposures to individuals or groups, and to corresponding data on health outcomes. Currently there is little linkage of exposure data with either personnel or medical records. An example of this can be seen in the variety of risk assessments made for $\mathrm{COSHH}$, noise and more generic risks. None of these records identify those exposed, nor are they linked to medical assessments carried out as a result of such exposures, for example, audiometry or health surveillance under COSHH. This lack of linkage between exposure, personnel and health records would significantly hinder attempts to monitor the effect of a particular exposure on health. Therefore, record systems should be developed in such a way that they can be readily linked to, and share data with, each other to facilitate exposure assessment and avoid duplicate data collection.

Retention and archiving of data

Retrospective studies of health are often necessary since there are varying latency 
periods between an exposure of concern and the manifestation of a health effect, for example, cancer. The retention of data useful for exposure assessment within and across the Services is variable. The data that should be potentially of most use, for example, $\mathrm{COSHH}$ assessments, noise assessments etc, are often only retained as long as they are current and are then discarded. This would particularly hinder retrospective studies. Furthermore, the retention of personnel and pay data is particularly variable, according to status (i.e rank), and between Services. This would bias retrospective studies of the effect of exposures on health, and could lead to misleading results, as exposures between ranks and officers may differ considerably. To avoid these problems a clear retention and archiving policy for all records across all Services, and procedures for implementing such a policy, should be developed.

\section{Conclusions}

Current collection and retention of data useful for exposure assessment in the UK Armed Forces is variable and, without substantial manual effort, would only allow limited health surveillance and epidemiological study of occupational health. The usefulness of many records is hampered by inconsistencies in the data collected, poor accessibility and linkage, and variability in the retention of the data. The use of these records could be greatly improved if the secondary uses of data were given greater consideration when developing primary data systems. Implementation of the suggested recommendations from this project would not only better enable exposure assessment ${ }_{20}^{c}$

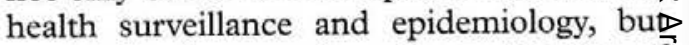
would also improve the primary function oB the data systems as well as potentially benefiting the health of Service personnel.

\section{Acknowledgments}

We gratefully acknowledge funding from the? Ministry of Defence for this project. W would also like to thank Mr Bob Fergusono Dr Dean Payne, and the members of the Health Surveillance Steering Group for theif assistance, Mrs Elaine Bottrill for providin\& administrative support, and all those whon we visited and gave their time to help witls the project.

\section{References}

1. Bricknell MCM. Options for future military healt surveillance systems. FR Army Med Corps 1999? 145: $80-83$.

2. WHO. Human exposure assessment. InternationaN Programme on Chemical Safety, Environmentæ⿸\zh14 Health Criteria, 214, Geneva: World Healtbु Organisation; 2000.

3. Rushton L, Betts D. Report from a workshop o요 the development of recommendations for the collection and retention of data by industry fog future epidemiological purposes. Luxembourg European Commission; 1997.

4. Checkoway H. Rapporteur's summary" epidemiologic evaluation of exposure-effeco relationships. In: Rappaport SM \& Smith TI editors. Exposure assessment for epidemiology ang hazard control. Michigan: Lewis Publishers; 1996 p. $67-73$.

5. IEH. An objective assessment of systems for thō collection and analysis of exposure dats Unpublished Report for the Defence Evaluatio 8 and Research Agency; 2000. Available from: URI http://www.le.ac.uk/ieh/

6. Beaumont PL, Dalrymple HL. A standard for the presentation of occupational exposure data. An Occup Hyg 1992; 36: 79-98. 